\title{
VINICIUS PRETTI
}

\section{AVALIAÇÃO CINTILOGRÁFICA DA REGENERAÇÃ̃ ÓSSEA PÓS-CIRÚRGICA EM COELHOS}

Dissertação de Mestrado apresentada ao Programa de Pós-Graduação Interunidades Bioengenharia - Escola de Engenharia de São Carlos / Faculdade de Medicina de Ribeirão Preto / Instituto de Química de São Carlos da Universidade de São Paulo como parte dos requisitos para a obtenção do título de mestre em Ciências.

Área de Concentração: Bioengenharia

Orientador: Prof. Dr. Lauro Wichert Ana

São Carlos, 2011 
ESTA DISSERTACAO DE MESTRADO FOI REDIGIDA SEGUNDO A NORMA VANCOUVER UTILIZANDO O SISTEMA DE CITAÇÃO AUTOR-DATA.

AUTORIZO A REPRODUÇÃO E DIVULGAÇÃO TOTAL OU PARCIAL DESTE TRABALHO, POR QUALQUER MEIO CONVENCIONAL OU ELETRÔNICO, PARA FINS DE ESTUDO E PESQUISA, DESDE QUE CITADA A FONTE.

Ficha catalográfica preparada pela Seção de Tratamento da Informação do Serviço de Biblioteca - EESC/USP

Pretti, Vinicius

P944a Avaliação Cintilográfica da regeneração óssea pós cirúrgica em coelhos / Vinicius Pretti ; orientador Lauro Wichert Ana. -- São Carlos, 2011.

Dissertação (Mestrado-Programa de Pós-Graduação e Área de Concentração Interunidades em Bioengenharia) - Escola de Engenharia de São Carlos, Faculdade de Medicina de Ribeirão Preto e Instituto de Química de São Carlos da Universidade de São Paulo, 2011.

1. Osteotomia. 2. Regeneração Óssea. 3. Coelhos. 4. Cintilografia Óssea. 5. Medicina nuclear. I. Título. 
Programa de Pós-Graduação Interunidades em Bioengenharia EESC / FMRP / IQSC

VINICIUS PRETTI

Título: "Avaliação cintilográfica da regeneração óssea pós-cirurgia em coelhos"



Aprovado em: $22,11,2011$

PROF. DR. LAURO WICHERT ANA (ORIENTADOR)

Resultado: Arronspo

PROF. DR. MARCUS VINICIUS SIMÕES

Resultado: APRO UADO

PROF. DR. PAULO MAZZONCINI DE AZEVEDO MARQUES

Resultado: Apher Ano
Faculdade de Medicina de Ribeirão Preto USP

Assinatura

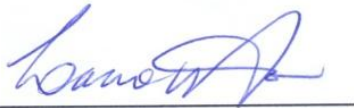

Faculdade de Medicina de Ribeirão Preto USP

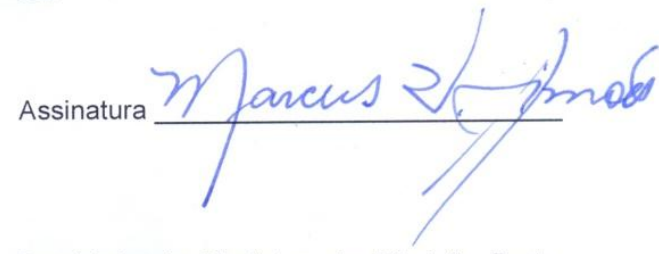

Faculdade de Medicina de Ribeirão Preto USP

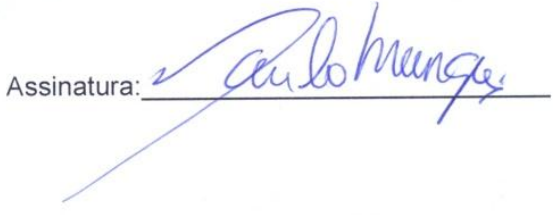




\section{DEDICATÓRIA}

Dedico esse trabalho aos meus país João e $\mathcal{N} e u z a$ que sempre me incentivaram e me encorajaram a seguir em frente e nunca desistir dos meus sonhos, e a minha esposa Talitha, por todo amor, paciência, força e presença durante esta jornada. Minha eterna gratídão! 


\section{AGRADECIMENTOS}

À Deus por me dar saúde e força para realização deste trabalho;

Aos meus pais João e $\mathcal{N} e u z a$ por sempre acreditarem em mim, por me proporcionarem toda educaçẫo, pela força de nunca me deixarem desistir, pela presença em todos os momentos da minha vida;

Ao meu orientador Prof. D r. Lauro Wichert Ana, por todo ensinamento, conselhos, paciência e acima de tudo confiança que depositou em mim;

ג̇ minha esposa, sempre ao meu lado, por toda sua força, paciência, compreensão e amor;

Ao Chíco do Caboratório de Bioengenharía da Faculdade de Medicina de Ríbeirão Preto;

$\mathcal{A}$ o $\mathcal{D}$ r. Alexandre yoneda por toda ajuda em cada etapa deste trabalho;

$\mathcal{A}$ todos os tecnólogos da Seção de Medicina Nuclear pelo eficiente trabalho;

$\mathcal{A}$ todos da Bioengenharia da EESC que de certa forma contribuiram para o desenvolvimento do trabalho. 


\section{RESUMO}

PRETTI,V. Avaliação Cintilográfica da regeneração óssea pós-cirúrgica em coelhos. 2011. 45 f. Dissertação (Mestrado) - Programa de Pósgraduação Interunidades em Bioengenharia - Escola de Engenharia de São Carlos / Faculdade de Medicina de Ribeirão Preto / Instituto de Química de São Carlos da Universidade de São Paulo - Universidade de São Paulo, 2011.

A regeneração óssea é um importante processo fisiológico e bioquímico que acontece no tecido ósseo em resposta a diferentes tipos de agressões. Sejam elas o trauma, infecções, excessos de demanda de carga, lesões expansivas, malformações vasculares e alterações metabólicas sistêmicas, em quaisquer destas situações a remodelação e regeneração óssea assumem grande importância dada a relevância do esqueleto para a saúde humana. Neste sentido, faz-se importante desenvolver técnicas de pesquisa que permita-nos estudar in vivo as alterações metabólicas que acontecem no tecido ósseo em diferentes condições. Neste sentido, nosso objetivo foi o de utilizar a técnica de cintilografia óssea para avaliar a osteogênese secundaria à osteotomia em um modelo animal de coelho da raça New Zealand. Para tanto desenvolvemos um estudo longitudinal, prospectivo, caso-controle, no qual as variáveis cintilográficas foram mensuradas tanto na pata operada (pata anterior direita) quanto na pata controle (pata anterior esquerda). A amostra foi constituída por um grupo de 10 coelhos, inicialmente, os quais foram submetidos à osteotomia, seguindo-se um período de avaliação de 12 semanas pós-operatórias, divididas em três etapas de imageamento, com 4, 8 e 12 semanas. Como resultados observamos: (A) a pata operada apresentou uma radiação externa significativamente maior do que a controle, ao uso do colimador pinhole, denotando aumento da biodistribuição e tropismo do radiofármaco para a pata operada; (B) Dentre os 3 momentos avaliados, a osteogênese foi máxima em 4 semanas e apresentou declínio significativo nas $8^{\mathrm{a}}$ e $12^{\mathrm{a}}$ semanas, denotando regeneração e resolução da lesão cirúrgica; (C) A pata controle também foi influenciada pela inatividade imposta pela pata operada. Este fato ficou evidenciado notadamente pela também redução da osteogênese na pata anterior esquerda (controle). Concluimos que a técnica da cintilografia óssea foi sensível ao diferenciar semi-quantitativamente a osteogênese na pata operada, nos três marcos temporais avaliados no presente estudo.

PALAVRAS-CHAVE: Osteotomia, Regeneração Óssea, Coelhos, Cintilografia Óssea, Medicina Nuclear. 


\section{ABSTRACT}

PRETTI,V. Scintigraphic Evaluation of bone healing postoperative in rabbits. 2011. 45 f. Dissertação (Mestrado) - Programa de Pós-graduação Interunidades em Bioengenharia - Escola de Engenharia de São Carlos / Faculdade de Medicina de Ribeirão Preto / Instituto de Química de São Carlos da Universidade de São Paulo - Universidade de São Paulo, 2011.

Bone healing is an important physiological and biochemical process that occurs in bone tissue in response to different types of aggression. Whether the trauma, infections, excessive load demand, expansive lesions, vascular malformations and systemic metabolic changes in any of these situations remodeling and bone regeneration are very important given the relevance of the skeleton to human health. In this sense, it is important to develop research techniques that allow us to study in vivo the metabolic changes that occur in the bone tissue under different conditions. In this sense, our goal was to use the technique of bone scintigraphy to evaluate osteogenesis secondary to osteotomy in an animal model of New Zealand rabbits. For this purpose we developed a longitudinal, prospective, case-control study, in which the scintigraphic variables were measured both in the operated paw (right paw) and the control paw (left paw). The sample consisted of a group of 10 rabbits, initially, which underwent osteotomy, followed by an evaluation period of 12 weeks after surgery, divided into three stages of imaging, 4, 8 and 12 weeks. As results show: (A) the operated paw external radiation was significantly higher than the control, through pinhole collimator, showing increased radiotracer biodistribution and tropism for the operated paw, (B) Among the three time intervals, the osteogenesis was maximal at 4 weeks and showed significant decline in the 8th and 12th week, showing regeneration and resolution of the surgical lesion, (C) The control paw was also influenced by the inactivity imposed by the operated leg. This fact was also evidenced by markedly reduced osteogenesis in the left paw (control). We conclude that the technique of bone scintigraphy was sensitive to differentiate semiquantitatively osteogenesis in the operated leg in three timeframes in the current study.

Keywords: Osteotomy, Bone healing, Rabbits, Bone scintigraphy, Nuclear medicine. 


\section{LISTA DE FIGURAS}

FIGURA 1 - Ampliação da imagem através do colimador Pinhole. 19

FIGURA 2 - Foto cirúrgica da osteotomia, retirada de um fragmento ósseo, no terço médio da ulna direita do coelho .23

FIGURA 3 - Fotos da rotina de transporte, acondicionamento, posicionamento e aquisição das imagens dos coelhos 24

FIGURA 4 - Gama Câmara Siemens Orbiter e o colimador Pinhole .26

FIGURA 5 - Figura apresentando imagens de cintilografia óssea obtidas com colimador pinhole do rádio e ulna de ambas as patas $\mathrm{D}$ e $\mathrm{E}$ 27

FIGURA 6 - Foto mostrando a radiografia da pata direita operada de um coelho e diagramas evidenciando as regiões de interesse para a semiquantificação à cintilografia óssea 


\section{LISTA DE GRÁFICOS}

GRÁFICO 1 - Médias de Intervalo de Tempo entre a Injeção do Radiofármaco e a Aquisição das Imagens de Cintilografia Óssea 31

GRÁFICO 2 - Contagens totais de radiação externa nas patas operada (direita) e controle (esquerda) através do colimador pinhole. .32

GRÁFICO 3 - Biodistribuição do radiofármaco nos tecidos moles de ambas as patas, controle e operada .33

GRÁFICO 4- Taxas de Contagem (ctgs/pixel) no osso inteiro e nos terços distal, médio e proximal dos ossos rádio e ulna, das patas controle e operada, nas quarta, oitava e décima segunda semana .36 


\section{LISTA DE SIGLAS}

\begin{tabular}{|c|c|}
\hline $\mathbf{c m}$ & centímetro \\
\hline mg & miligrama \\
\hline kg & kilograma \\
\hline${ }^{18} \mathrm{~F}$ & flúor-18 \\
\hline${ }^{45} \mathrm{Ca}$ & cálcio-45 \\
\hline${ }^{89} \mathrm{Sr}$ & estrôncio-89 \\
\hline${ }^{85} \mathrm{Sr}$ & estrôncio-85 \\
\hline${ }^{99 m} \mathrm{Tc}$ & tecnécio-99m \\
\hline MDP & metileno difosfatado \\
\hline ROI & Região de Interesse \\
\hline Kev & Míl elétrons-volt \\
\hline $\mathrm{mCi}$ & miliCurie \\
\hline $\operatorname{ctgs}$ & contagens \\
\hline h & horas \\
\hline DP & Desvio Padrão \\
\hline
\end{tabular}




\section{Sumário}

LISTA DE FIGURAS

LISTA DE GRÁFICOS

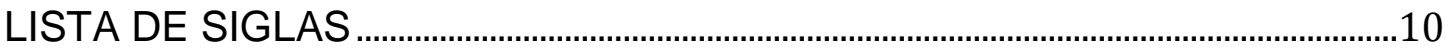

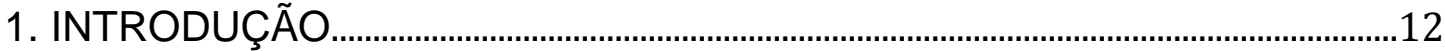

1.1. ANATOMIA E FISIOLOGIA DA REGENERAÇÃO DO TECIDO

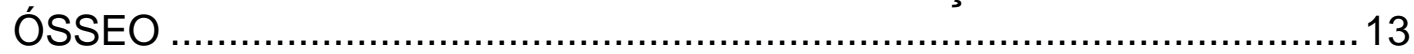

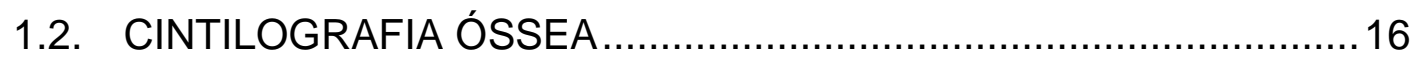

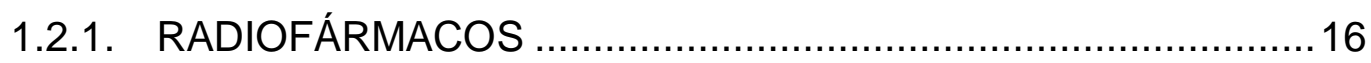

1.2.2. OS AGENTES DE FOSFATO ........................................... 17

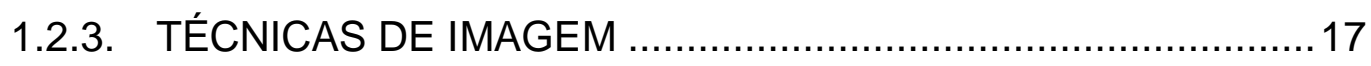

1.2.4. COLIMADOR ............................................................ 18

1.2.4.1. COLIMADOR PINHOLE ................................................ 18

1.3. RACIONAL DO PROJETO ................................................20

2. OBJETIVOS

3. MATERIAIS E MÉTODOS .......................................................................................22

4. RESULTADOS

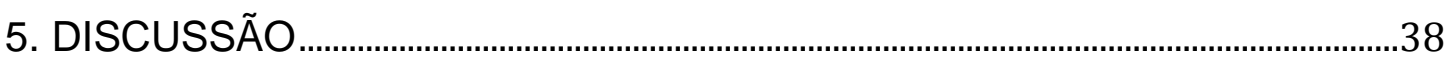

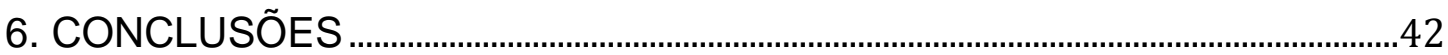

7. LIMITAÇÕES DO ESTUDO E SUGESTÕES PARA PESQUISAS

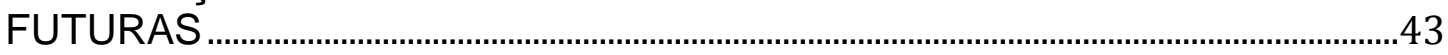

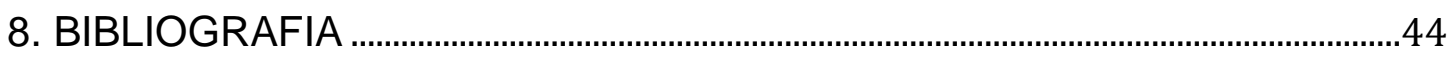




\section{INTRODUÇÃO}

O esqueleto tem uma variedade de funções. Os ossos do esqueleto proporcionam um suporte estrutural para o resto do corpo, permite a circulação e locomoção através de alavancas para o músculos, protegem os órgãos internos vitais e estruturas, fornecem manutenção da homeostase mineral e equilíbrio ácido-base, servem como um reservatório de fatores de crescimento e citocinas, e proporcionam o ambiente ideal para hematopoiese pela medula óssea (TAICHMAN, 2005). tecido ósseo tem propriedades estruturais muito interessantes. Isso está essencialmente relacionado à sua composição estrutural: hidroxiapatita, colágeno, quantias pequenas de proteoglicanas, proteínas não colágenas e água (LUCCHINETTI, 2001). Os componentes inorgânicos são principalmente responsáveis pela força de compressão e dureza, enquanto componentes orgânicos provêem as propriedades de tensão.

Há dois tipos de ossos: cortical (compacto) e trabecular (esponjoso). Aproximadamente $80 \%$ da massa óssea esquelética é constituída por osso cortical, e $20 \%$ por esponjoso, que ocupa a maior superfície.

O osso cortical é formado por camadas densas calcificadas, constitui as corticais dos ossos longos, também encontrado na camada externa de todos os ossos e é o principal componente do esqueleto apendicular (periférico). Sua função primaria é a sustentação e a proteção do esqueleto (CALIXTO, 2007).

O osso trabecular está presente nos ossos do esqueleto axial e nas epífises dos ossos longos, ele ocupa o espaço interno entre as corticais dos ossos e é constituído por uma rede de barras ósseas horizontais e verticais chamadas de trabéculas, dispostas como uma colméia (GINEBRA, 2000).

Os ossos longos são constituídos por um eixo oco, ou diáfise; metáfises em forma de cone abaixo da cartilagem de crescimento e epífises 
arredondados acima das placas de crescimento. A diáfise é composta principalmente de osso cortical denso, enquanto que a metáfise e epífises são compostas de malha trabecular recoberto por uma casca relativamente fina de cortical denso (CLARKE, 2008).

O periósteo é uma bainha de tecido conectivo fibroso circunda a superfície externa do osso cortical, exceto nas articulações onde o osso é revestido por cartilagem articular, que contém vasos sanguíneos, fibras nervosas, e os osteoblastos e osteoclastos. O periósteo está intimamente ligado à superfície externa do osso cortical por espessas fibras colágenas, chamadas fibras Sharpeys, que se estendem no tecido ósseo subjacente. $O$ endósteo é uma estrutura membranosa que cobre a superfície interna do osso cortical, trabecular óssea e dos canais sanguíneos (canais de Volkman) presentes no osso. O endósteo está em contato com a medula óssea, o osso trabecular, e canais dos vasos sanguíneos e contém vasos sanguíneos, osteoblastos e osteoclastos (ERIKSEN, 1994).

O osso é um material dinâmico que é exposto habitualmente a ambientes mecânicos que desafiam sua integridade estrutural. Há várias causas que geram fratura óssea, porém, em contraste com materiais inertes, o osso pode regenerar-se formando tecido novo onde foi danificado.

\subsection{ANATOMIA E FISIOLOGIA DA REGENERAÇÃO DO TECIDO ÓSSEO}

A consolidação óssea é um processo único no corpo humano que lembra as fases embrionárias do desenvolvimento. $\mathrm{Na}$ realidade, estes estágios são retomados durante a cicatrização da fratura e o processo de formação do osso é reiniciado no caso de uma lesão óssea. (Ferguson et al., 1999). O evento reparador é integrado com a formação de um tecido que é idêntico ao original, ao contrário de outras partes do aparelho locomotor, que respondem a uma lesão com formação de tecido cicatricial. Fundamentado 
nessa resposta à lesão, todo o processo é efetivamente regenerativo e não apenas um processo de reparação (TOSOUNIDIS et all, 2009).

Em termos histológicos clássicos o reparo de fratura pode ocorrer através de dois processos diferentes: a cicatrização primária e secundária. A cascata de eventos que ocorrem durante a cicatrização óssea depende de muitas variáveis como fatores de crescimento locais, os nutrientes e os hormônios, o ambiente elétrico e estabilidade mecânica no local da lesão (FERGUSON et al, 1999; CAO, 2004). Na consolidação da fratura todas as estruturas que participam do trauma (medula óssea, periósteo, córtex e tecidos moles) contribuem para cura. O grau de envolvimento de cada um dos estes elementos define o tipo de regeneração (AUGAT et al, 1998).

A regeneração primária envolve uma tentativa direta do córtex para restabelecer a interrupção. O osso em um lado do córtex tem que se unir com o osso no outro lado do córtex a fim de restabelecer a continuidade mecânica. Este processo parece acontecer somente nos casos de extrema estabilidade, desconsiderando-se a amplitude da interrupção entre os fragmentos, havendo a tentativa do osso se formar diretamente (EINHORN, 1998).

Na ocorrência de um impacto ou lesão, quando o osso absorve energia além de sua tenacidade, uma fratura acontece ao longo da linha de menor resistência. O impacto fere a medula óssea local, o periósteo, os tecidos moles adjacentes e rompem-se os vasos sanguíneos. Primeiramente a fratura sensibiliza as células locais e as capacita a responder melhor as mensagens e estímulos sistêmicos, em seguida, lança mensageiros bioquímicos e biofísicos a fim de que as células possam responder. Esta sensibilização biológica dura por volta de 7 dias (FROST, 1989).

$\mathrm{Na}$ fase de inflamação, ocorre a formação de hematoma e a hemorragia é o resultado do rompimento do periósteo e dos vasos sanguíneos no local da fratura. As extremidades dos vasos sanguíneos sofrem trombose e são lançadas enzimas tornando o ph ácido. Macrófagos, leucócitos e outras células inflamatórias invadem a área (EINHORN, 1998). 
$\mathrm{Na}$ fase de formação do calo transitório, as células são estimuladas a iniciar a produção de novos vasos sanguíneos, fibroblastos, material intracelular e células de apoio, que formam tecido de granulação no espaço entre os fragmentos da fratura, fase esta que dura aproximadamente 2 semanas (EINHORN, 1998). A formação e mineralização do calo podem durar cerca de 4 a 16 semanas, podendo ser um processo mais rápido em crianças e em osso esponjoso (CRENSHAW, 1992).

O estágio de mineralização de calo transitório começa aproximadamente 1 semana após a formação de calo suave novo. O aumento de oxigênio conduz à produção de osteóide que consiste, principalmente, em hidroxiapatita de cálcio opaco que o faz radiologicamente visível. A presença de osteóide provê rigidez dentro do calo.

A regeneração secundária de fraturas envolve os estágios clássicos de remodelamento, isto é, inflamação, formação do calo, mineralização e remodelação (LIND,1998).

O osso é um tecido conjuntivo muito especializado e que, devido à intensa atividade celular, se desenvolve por meio da osteogênese. As células que constituem a matriz óssea são os osteócitos que se situam em cavidades ou lacunas no interior da matriz, os osteoblastos são as células responsáveis pela síntese da matriz e os osteoclastos, células gigantes multinucleadas, estão relacionadas ao processo de remodelação óssea.

Durante a regeneração óssea as células osteoblásticas sintetizam um material orgânico inicialmente amorfo, que logo em seguida torna-se densamente fibroso chamado osteóide. Os cristais de hidroxiapatita de cálcio são então depositados no osteóide, que se transforma na matriz óssea propriamente dita. Os osteoblastos ficam aprisionados nessa matriz onde diferenciam-se em osteócitos, desse modo, precursores dos cristais de hidroxiapatita de cálcio difundem-se nas fibras colágenas e no cimento e o osteóide converte-se em osso. 


\subsection{CINTILOGRAFIA ÓSSEA}

A cintilografia óssea é uma das técnicas mais estudadas da medicina nuclear.

Devido à sensibilidade com a qual as alterações na fisiologia do osso podem ser mostrada, o escaneamento ósseo se tornou parte integral na investigação de uma série de distúrbios esqueléticos. A cintilografia óssea indica as alterações metabólicas produzidas pela modificação na vascularização do osso e na atividade osteoblástica.

Em muitos casos, o estudo de radionuclídeos irá revelar uma anomalia muito antes da alteração radiológica, em alguns isso pode indicar qual área deve ser mais investigada, enquanto em outros, pode ser de valor, demonstrando um padrão de mudanças anormais que reforçará o parecer radiológico. Também pode indicar se a lesão radiologicamente demonstrável é de significado clínico. A consciência da indicação da cintilografia óssea e as alterações características encontradas é obrigatório na investigação de doenças do esqueleto, qualquer que seja a etiologia (STOREY et al, 2004).

\subsubsection{RADIOFÁRMACOS}

A propensão para certos radionuclídeos para se concentrar no osso foi reconhecido pela primeira vez no início de 1920 com a observação dos efeitos da ingestão de sais pelos pintores de mostradores de relógios luminosos e demonstração posterior de que a captação foi no osso. Os estudos metabólicos com radionuclideos foram iniciados em 1935 com a P32 e ortofosfato estendida no início dos anos 1940 com o uso do flúor-18 $\left({ }^{18} \mathrm{~F}\right)$, cálcio-45 $\left({ }^{45} \mathrm{Ca}\right)$ e estrôncio-89 $\left({ }^{89} \mathrm{Sr}\right.$ ) (CHIEVITZ e HEVESY, 1935). Uma grande variedade de radionuclídeos foram avaliados nas suas propriedades em busca de ossos, nos anos seguintes. As primeiras imagens de ossos foi obtida com estrôncio-85 $\left({ }^{85} \mathrm{Sr}\right.$ ) (FLEMING et al, 1961). Posteriormente estudos clínicos indicaram que o procedimento foi capaz de detectar lesões nos ossos bem antes que as alterações radiológicas se tornassem aparente. Desvantagens deste radionuclídeo incluiu uma alta dose 
de radiação para o paciente e a necessidade de aguardar por pelo menos 2448 horas para permitir a excreção da radioatividade desvinculado antes de realizar o exame. Um grande avanço ocorreu com a introdução de ${ }^{87 \mathrm{~m}} \mathrm{Sr}$, devido à sua curta meia-vida, mas um nível de fundo persistente da atividade nos tecidos moles ainda não gerava imagens satisfatórias (CHARKES,1969). Como um agente gerador de produção, outro problema era o custo elevado. A alternativa, ${ }^{18} \mathrm{~F}$, foi muito mais satisfatório, com um meia-vida sanguínea rápida e a visualização do esqueleto melhorada (BLAU et al,1962). Além do custo (produzida pela ciclotron), a principal desvantagem deste radionuclídeo foi a disponibilidade limitada devido à sua curta meia-vida de 1,83 horas.

A experiência com ${ }^{18} \mathrm{~F}$ deixou claro que a cintilografia óssea ofereceu tanto quanto outros procedimentos da medicina nuclear, que havia sido adotado rapidamente em prática de rotina. Grande parte da importancia destas técnicas derivam do uso de tecnécio-99m $\left({ }^{99 \mathrm{~m}} \mathrm{Tc}\right)$ - radiofármaco marcador, refletindo as propriedades ideais deste radionuclídeo para fins de imagem. A busca por um ${ }^{99 \mathrm{~m}} \mathrm{Tc}$ marcador ósseo foi centrado nos complexos de fosfatos, tendo em conta o efeito da fosfonatação no tratamento de distúrbios ósseos (STOREY et al, 2004).

\subsubsection{OS AGENTES DE FOSFATO}

Muitos agentes passaram por ampla avaliação e comparação, mas o metileno difosfatado (MDP), continua a ser o agente mais utilizado (SUBRAMANIAN et al,). Este radiofármaco ganhou popularidade por causa da meia vida sanguínea mais rápida e maior afinidade esquelética.

\subsubsection{TÉCNICAS DE IMAGEM}

As imagens cintilográficas foram obtidas com uma gama-câmara de grande campo de visão (GCA-601, Toshiba, Japão) equipado com um colimador Pinhole (140 keV do pico, 20\% energia de janela) a uma distancia 
de $3 \mathrm{~cm}$ da pata operada e controle. Os animais foram imobilizados durante a imagem de aquisição com Ketamina/Xilazina. Dez mCi de tecnécio 99m marcado com metileno difosfonado (MDP) foi injetado por via intravenosa na veia da orelha. A imagem de fase óssea foi obtida em três horas. Tanto a distracção áerea e na perna contralateral normal foram incluídos no campo de visão. Todos os dados foram transmitidos para o computador para relatar. As imagens foram analisadas visualmente e semiquantitativa.

\subsubsection{COLIMADOR}

O colimador é a primeira parte da gamma-câmara de cintilação encontrados pelo fóton depois que deixa o paciente. O objetivo do colimador é definir o campo geométrico de visão do cristal e, especificamente, definir a direção desejada dos raios gama para captação no mesmo. Justamente porque raios-x e raios gama na faixa de energia utilizada em medicina nuclear não podem ser focados usando uma lente, a única maneira de determinar a direção dos fótons é de colimação de absorção, ou seja, absorvendo todos os fótons que não estão viajando na direção correta. Colimação de absorção é muito ineficiente, pois apenas uma pequena fração (cerca de 1 em 10.000) dos fótons emitidos estará viajando na direção correta. O colimador discrimina os fótons indesejados apenas em função da sua direção. O colimador não faz distinção entre fótons primários e dispersos ou entre fótons de energias diferentes. O analisador de altura de pulso é usado para discriminar os fótons espalhados e outros fótons indesejados que chegam ao detector. Colimadores para gamma-câmaras de cintilação estão disponíveis em quatro tipos básicos: pinhole, pinhole paralelo, convergentes e divergentes.

\subsubsection{COLIMADOR PINHOLE}

O principal uso do colimador pinhole é para objetos pequenos, como imagem da tireóide e ossos da mão e dos pés. Nesta aplicação, oferece a 
vantagem de ampliação da imagem quando a distância do objeto da abertura é menor que a distância do detector para a abertura. A ampliação geométrica permite a resolução de objetos menores do que a resolução intrínseca da gama câmara, que é particularmente útil em lesões tão pequenas quanto 3-5 mm (FIGURA 1). O colimador pinhole também oferece flexibilidade no posicionamento do paciente e é útil na obtenção imagens oblíquas. $O$ colimador pinhole também têm sido utilizado para ampliar pequenas estruturas em pacientes pediátricos (BAHK,1994).

A principal desvantagem do colimador pinhole é a baixa contagem. $O$ diâmetro da abertura do pinhole é de $3-6 \mathrm{~mm}$. Qualquer aumento deste tamanho para elevar os resultados da taxa de contagem gera uma diminuição correspondente da resolução espacial (MANDELL et al, 1990).

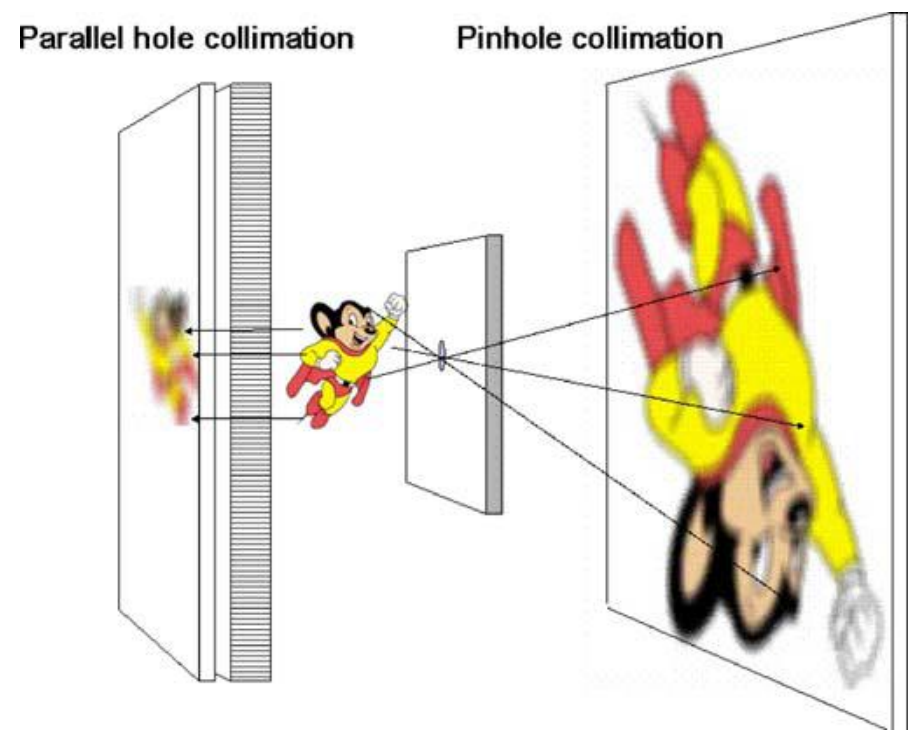

FIGURA 1-Ampliação da imagem através do colimador pinhole comparado ao método convencional 


\subsection{RACIONAL DO PROJETO}

Diante do acima exposto, o presente projeto visa investigar a sensibilidade e a plausibilidade biologica da cintilografia óssea como técnica de avaliação do metabolismo ósseo com diferentes condicoes. O domínio do protocolo de aquisição, processamento e analise de imagens cintilográficas ósseas em diferentes contextos normais ou patológicos poderá servir como importante ferramenta de pesquisa para engenheiros, médicos ortopedistas e fisiatras, fisioterapeutas, terapeutas ocupacionais e demais profissionais. Neste sentido, elencamos abaixo os principais objetivos deste estudo. 


\section{OBJETIVOS}

2.1. Avaliar a biodistribuição global e relativa do radiofármaco MDP${ }^{99 \mathrm{~m}} \mathrm{Tc}$ em ambas as patas dianteiras dos coelhos (controle e operada), através da mensuração da radiação externa detectada através do colimador pinhole;

2.2. Avaliar a biodistribuição relativa do radiofármaco MDP- ${ }^{99 \mathrm{~m}} \mathrm{Tc}$ nos tecidos moles de ambas as patas, controle e operada, baseando-se agora nas imagens cintilográficas obtidas das mesmas.

2.3. Avaliar a osteogênese (biodistribuição relativa do radiofármaco MDP- ${ }^{99 m} \mathrm{Tc}$ ) nos ossos rádio e ulna, de ambas as patas, controle e operada, baseando-se nas imagens cintilográficas obtidas das mesmas;

2.4. Avaliar as osteogênese nos ossos rádio e ulna, na $4^{\mathrm{a}}$, $8^{\mathrm{a}}$ e $12^{\mathrm{a}}$ semanas, com o intuito de analisar o processo dinâmico de regeneração óssea na pata operada. 


\section{MATERIAIS E MÉTODOS}

\subsection{Desenho do Estudo:}

Este trabalho constituiu-se em um estudo longitudinal, prospectivo, caso-controle, no qual as variáveis cintilográficas foram mensuradas tanto na pata operada (pata anterior direita) quanto na pata controle (pata anterior esquerda). A amostra foi constituída por um grupo de 10 coelhos submetidos à intervenção cirúrgica (osteotomia), seguindo-se um período de avaliação de 12 semanas pós-operatórias. Para este trabalho, os materiais utilizados incluíram modelo animal (coelhos), radioisótopo (tc99m), fármaco (MDP), sedativos (Ketamina, Xllazina), material cirúrgico e a utilização de uma Gama-Camara (câmara de cintilação).

\subsection{Modelo Experimental:}

Foram utilizados 10 coelhos machos da raça New Zealand os quais tiveram a pata dianteira direita operada onde foi feito uma osteotomia de ressecção no osso ulna, numa extensão de $2 \mathrm{~cm}$ localizada na junção do seu terço médio com o distal (FIGURA 2). Em seguida o canal medular proximal e distal era bloqueado com cera óssea e a falha preenchida com Gelfoam®. 
FIGURA 2 - Foto cirúrgica da osteotomia, retirada de um fragmento ósseo, no terço médio da ulna direita do coelho.

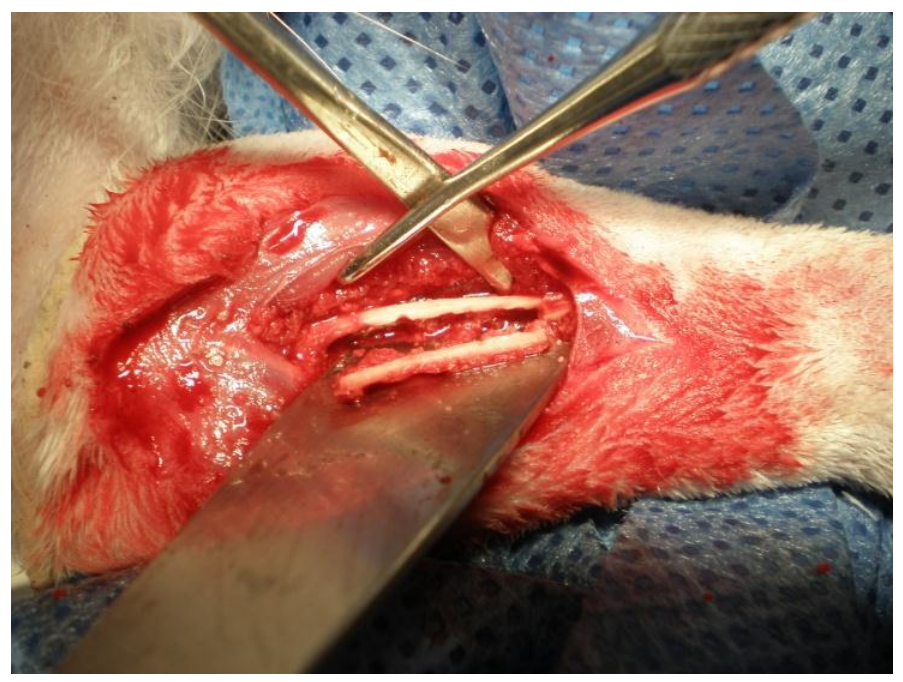

Os coelhos foram acomodados em gaiolas individuais com ração controlada e água à vontade. Nos intervalos de 4, 8 e 12 semanas, eram submetidos à cintilografia óssea. Depois de anestesiados (Ketamina/Xilasina) e vestindo fraldas, os coelhos foram injetados no centro cirúrgico do Departamento de Bioengenharia da Universidade de São Paulo por via endovenosa com o radiofármaco MDP- ${ }^{99 m} \mathrm{Tc}$ (abaixo descrito) e com um mínimo de 3 horas de antecedência ao exame cintilográfico. Após injetados os coelhos foram acondicionados em gaiolas (FIGURA 3-A) e transportados de carro até a entrada do Hospital das Clinicas da Faculdade de Medicina de Ribeirão Preto onde eram colocados em carrinhos e levados à seção de Medicina Nuclear.

Certificamos que o Protocolo para Uso de Animais em Experimentação $n^{\circ}$ 080/2008, sobre o projeto intitulado "Utilização do plasma rico em plaquetas autógenas nas falhas ósseas - avaliação da regeneração óssea em estudo experimental com animais", sob a responsabilidade do Professor Doutor Cláudio Henrique Barbieri e está de acordo com os Princípios Éticos na Experimentação Animal adotado pelo Colégio Brasileiro de Experimentação Animal (COBEA) e foi APROVADO pela COMISSAO DE ETICA EM EXPERIMENTACAO ANIMAL (CETEA) em reunião de 15 de dezembro de 2008. 
FIGURA 3 - Fotos da rotina de transporte, acondicionamento, posicionamento e aquisição das imagens dos coelhos.

\begin{tabular}{|l|l|}
\hline & $\begin{array}{l}\text { (A) Transporte seguro e menos estressante dos } \\
\text { coelhos para a Seção de Medicina Nuclear. }\end{array}$ \\
\hline (B) Posicionamento do orifício do colimador pinhole \\
sobre a pata dianteira esquerda (controle).
\end{tabular}

\subsection{Intervenção Cirúrgica:}

Os coelhos foram anestesiados com cloridrato de Ketamina (35mg/kilo) e Xilazina (9mg/kilo) injetados via intramuscular. Foi operada a pata dianteira direita de todos os coelhos, utilizando uma via de acesso ventral. O rádio foi exposto e desperiostizado em toda a sua circunferência numa extensão de $4 \mathrm{~cm}$ de comprimento. Em seguida era feita uma osteotomia de ressecção envolvendo apenas a hemi-circunferencia ventral do osso, numa extensão de $2 \mathrm{~cm}$ localizada na junção do terço médio com o distal. Em seguido, o canal medular proximal e distal era bloqueado com cera 
óssea $($ Ethicon $\AA$ ) e a falha óssea preenchida com Gelfoam $\AA$. Não foi necessário o emprego de exanguinação e garroteamento do membro operado.

\subsection{A técnica da Cintilografia Óssea:}

A cintilografia óssea foi obtida a partir das patas anteriores dos coelhos após os mesmos terem sido injetados em uma punção venosa, a dose de $10 \mathrm{mCi}$ do radiofármaco metilenodifosfonado (MDP) marcado com Tecnécio-99m ( $\left.{ }^{99 \mathrm{~m}} \mathrm{Tc}\right)$. O MDP é um fármaco com tropismo pela matriz orgânica do osso e concentra-se em maior quantidade, quanto maior é a osteogênese. $\mathrm{O}^{99 \mathrm{~m}} \mathrm{Tc}$ é um radioisótopo que emite radiação gama pura, com 140 Kev de energia e possui meia vida física de 6 horas.

Após a injeção do MDP- ${ }^{99 \mathrm{~m}} \mathrm{Tc}$ os coelhos mantiveram-se em repouso por 3 horas, para permitir a absorção do traçador pela matriz orgânica do tecido ósseo. Neste momento, então, foi executada a técnica de imageamento das patas anteriores dos coelhos. Após serem colocados em uma placa acrílica para posicionamento e maior conforto, acondicionamos os coelhos sedados sob o ápice do colimador pinhole (FIGURA 3 - B e C), e as imagens das patas foram magnificadas nos detectores. Procedemos à aquisição de uma imagem estática de cada pata pelo tempo de 600 segundos (10 minutos) em uma matriz $128 \times 128$, sem zoom digital, apenas a magnificação física do colimador pinhole. $O$ fotopico do equipamento foi centrado em $140 \mathrm{Kev}$ e a janela de energia foi configurada para $20 \%$. As imagens cintilográficas obtidas podem ser observadas na FIGURA 4, as quais foram utilizadas para gerar regiões de interesse para o estudo de semiquantificação, como o que se observa no ROI-01 (Region of Interest numero 1). 
FIGURA 4 - Gama Câmara Siemens Orbiter e o colimador Pinhole.

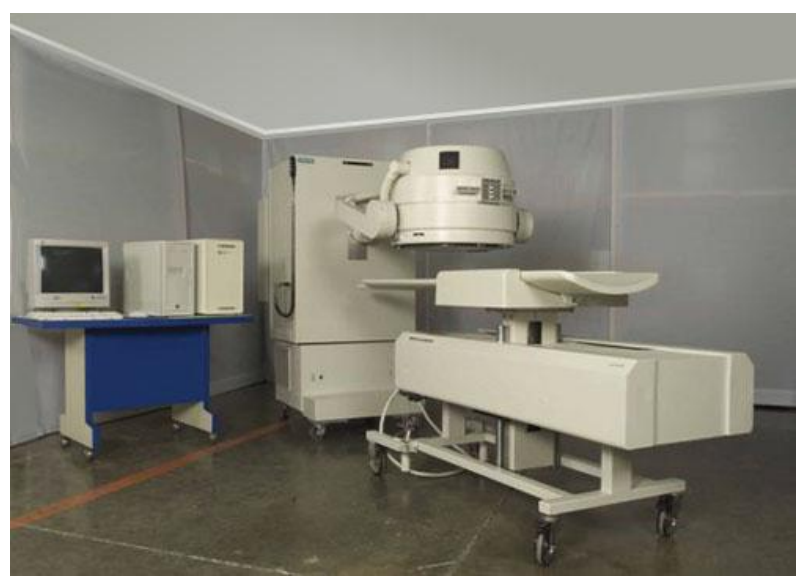

(A)

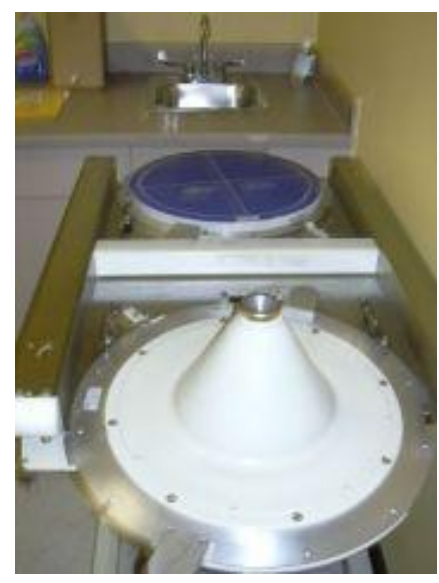

(B)

LEGENDA: Em (A) Gama Câmara Siemens Orbiter (Siemens, Erlangen, Alemanha) à qual se acopla o colimador pinhole (B), o qual possui a propriedade física de magnificar a imagem no detector e na tela da Workstation do objeto que Ihe é colocado diante do orifício de colimação (ápice do cone do colimador). 
FIGURA 5 - Figura apresentando imagens de cintilografia óssea obtidas com colimador pinhole do rádio e ulna de ambas as patas $\mathrm{D}$ e $\mathrm{E}$.

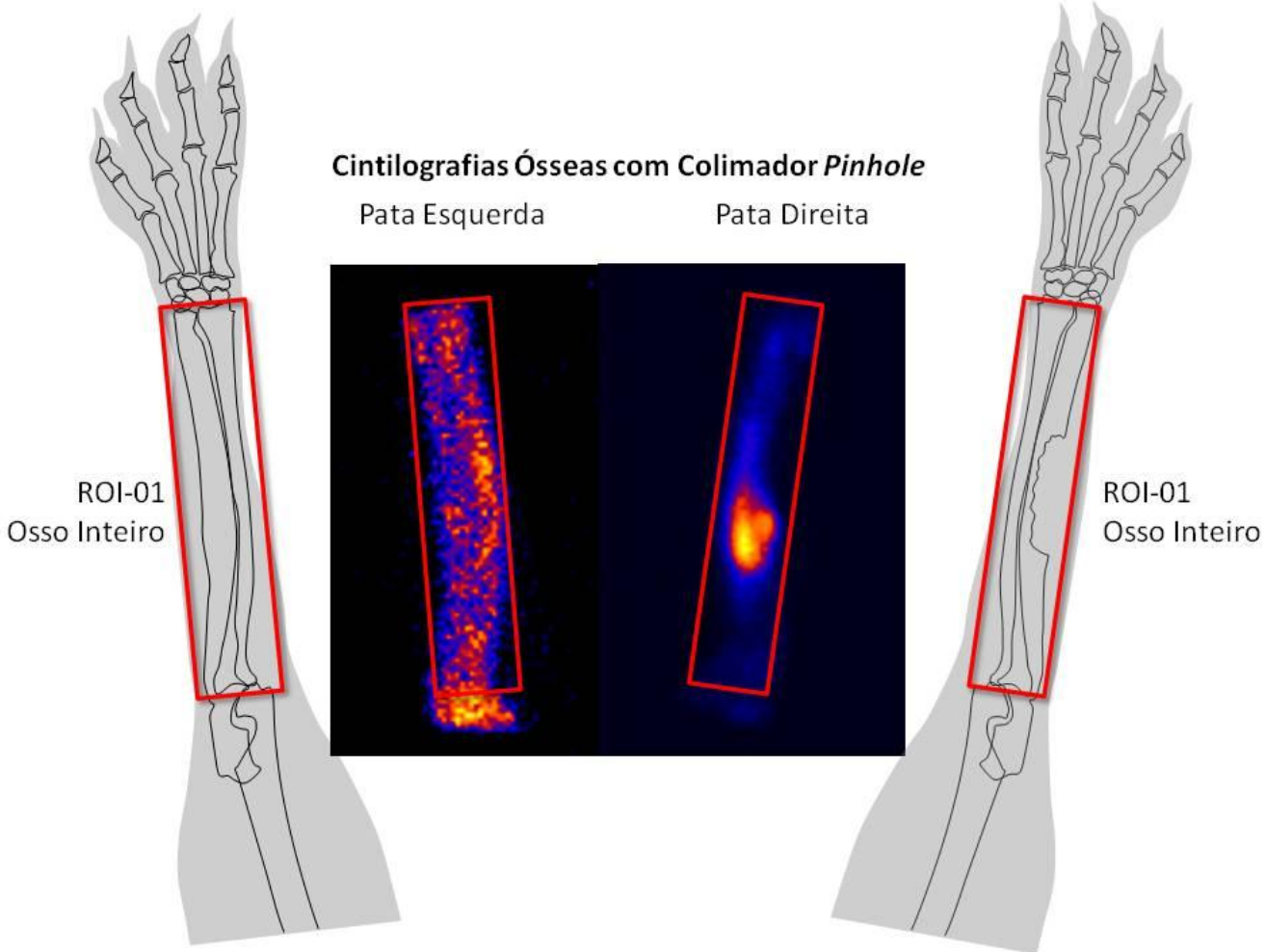

LEGENDA: Imagens de cintilografia óssea obtidas com colimador pinhole, tanto da pata controle (esquerda) e operada (direita). $\mathrm{Na}$ imagem cintilográfica da pata esquerda observe a distribuição aproximadamente homogênea do radiofármaco MDP$99 \mathrm{mTc}$ ao longo da extensão dos ossos rádio e ulna. Na imagem cintilográfica da pata direita, observe o intenso acúmulo do radiofármaco na projeção do terço médio da pata anterior direita, local onde foi realizada a osteotomia. A intensidade de contagem nesta área operada é tão elevada que relativamente leva a um exibição normalizada menor da concentração do radiofármaco nos outros terços proximal e distal da pata direita. 


\subsection{Avaliação da biodistribuição relativa do radiofármaco MDP. ${ }^{99 m}$ Tc nas patas controle e operada:}

Antes de analisar semi-quantitativamente as imagens cintilográficas dos ossos das patas dianteiras dos coelhos, procedemos ao registro da "Contagem Total ao Pinhole". Trata-se da contagem total de raios gama proveniente de cada pata e que atravessaram o orifício do colimador pinhole, cintilaram no detector da gama-câmara e em seguida foram exibidos numericamente no display do software da Workstation NXTP (FIGURA 3-D). O objetivo desta contagem foi o de avaliar a atividade radioativa global em cada uma das patas, diante do detector.

Esta contagem foi obtida posicionando-se o centro de cada pata (região mediana entre o punho e o cotovelo) a $2 \mathrm{~cm}$ do orifício do colimador pinhole. Em seguida, adquiriu-se imagem estática de cada pata durante 0 período de 600 segundos (10 minutos), sendo que ao final desta aquisição o Software de processamento da Workstation NXTP apresentou no display o número de raios gama que foram registrados naquela incidência. Ou seja, obtivemos assim a "Contagem Total ao Pinhole". Esta contagem foi adquirida nas $4^{\mathrm{a}}, 8^{\mathrm{a}}$ e $12^{\mathrm{a}}$ semanas pós-operatórias.

Estas imagens estáticas foram então utilizadas para a obtenção das semi-quantificações relativas a quatro áreas de estudo nas patas anteriores dos coelhos e que foram desenhadas na forma de "Regiões de Interesse" (Regions of Interest): ROI-01, que envolveu toda a extensão dos ossos da pata anterior (ossos ulna e rádio), e segmentos deste ROI-01 que foram divididos em terças partes, onde ROI-02 envolveu o terço distal, ROI-03 envolveu o terço médio e o ROI-04 envolveu o terço proximal. Estes ROls foram desenhados tanto na pata controle (pata esquerda) quanto na pata operada (pata direita). (FIGURA 5)

Os dados numéricos semi-quantitativos foram colocados em tabelas e suas informações foram utilizadas para compor os gráficos comparativos que apresentamos na seção RESULTADOS. 
FIGURA 6 - Foto mostrando a radiografia da pata direita operada de um coelho e diagramas evidenciando as regiões de interesse para a semi-quantificação à cintilografia óssea.
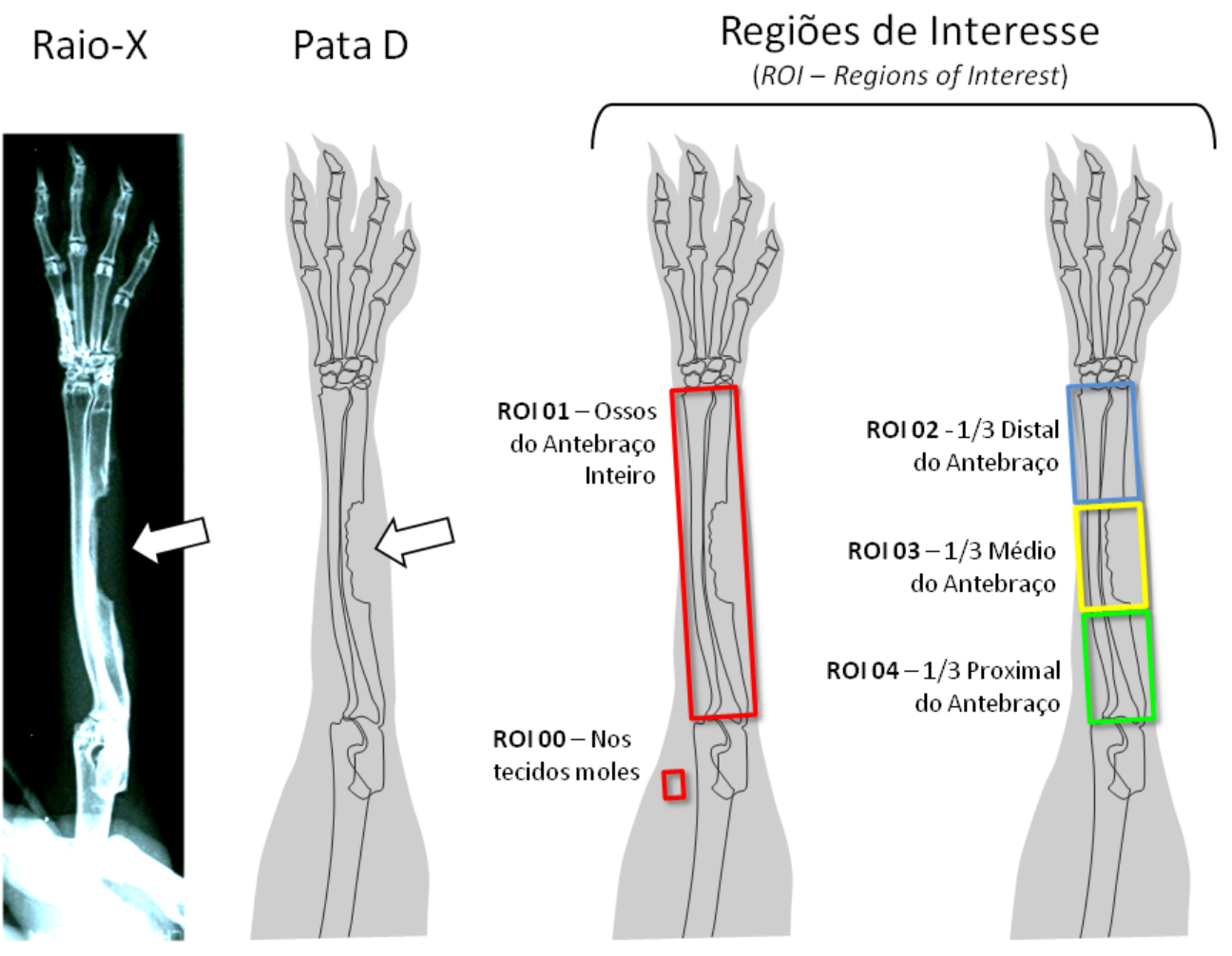

LEGENDA: A imagem de "Raio-X" e o diagrama da pata direita ("Pata D") evidenciam o local onde foi realizada a lesão cirúrgica ou osteotomia da ulna (Seta). Outros diagramas da pata dianteira direita evidenciam as "Regiões de Interesse" ou ROIs (Regions of Interest) utilizadas para a semi-quantificação da atividade osteogênica nos ossos rádio e ulna dos coelhos. ROI-00 foi desenhado sobre os tecidos moles; ROI-01 foi posicionado sobre a extensão quase total dos ossos rádio e ulna, excluindo-se as regiões do punho e do cotovelo; os demais ROls foram desenhados em terças partes do ROI-01, resultando no ROI-02 (1/3 distal), ROI-03 (1/3 médio) e ROI-04 (1/3 proximal dos ossos rádio e ulna). 


\section{RESULTADOS}

\subsection{Avaliação da homogeneidade dos intervalos de tempo de aquisição das imagens entre os grupos de 4, 8 e 12 semanas:}

Considerando que a diferença da taxa de contagem entre os ROls dos ossos e dos tecidos moles será maior quanto maior o tempo decorrido depois da injeção (isto devido ao clareamento da radioatividade nos tecidos moles), procedemos ao cálculo para determinar se os intervalos de tempo entre a injeção e aquisição nos grupos de 4, 8 e 12 semanas foram iguais.

Nossos resultados evidenciaram intervalo de tempo entre a injeção do radiofármaco e a aquisição das imagens de 04:18 +/- 00:31h para o Grupo de 4 semanas, 04:08+/-00:42h para o Grupo de 8 semanas e de 04:08+/-00:38h para o grupo de 12 semanas. Estes intervalos temporais não apresentaram diferença significante entre os Grupos de 4, 8 e 12 semanas (One-Way ANOVA, $p \leq 0,78)$. Isto é, os 3 grupos são praticamente homogêneos, embora o Grupo de 4 semanas tenha apresentado um intervalo ligeiramente maior. 
GRÁFICO 1 - Médias de Intervalo de Tempo entre a Injeção do Radiofármaco e a Aquisição das Imagens de Cintilografia Óssea.

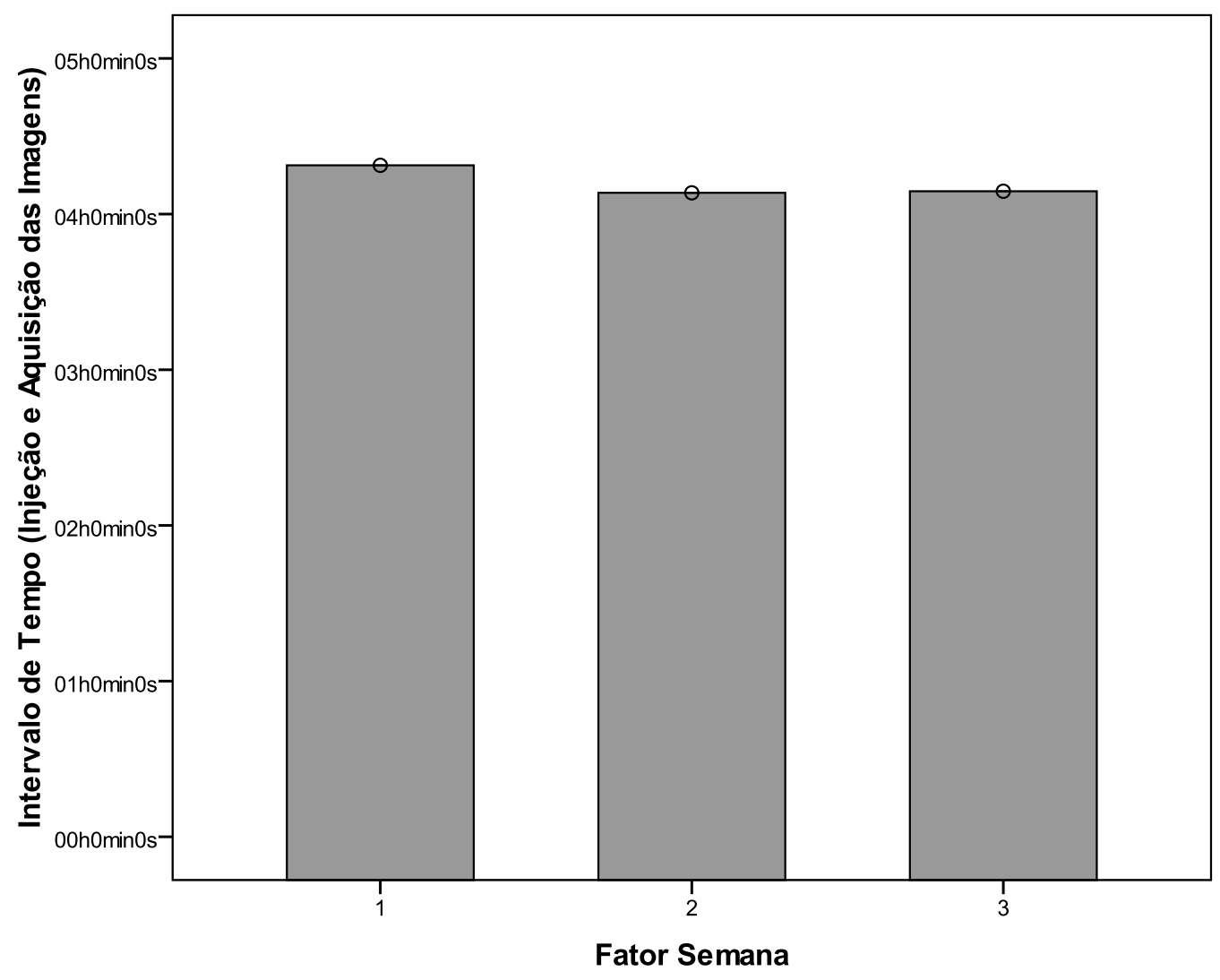

4.1. Avaliação da biodistribuição global e relativa do radiofármaco MDP${ }^{99 \mathrm{~m}}$ Tc em ambas as patas dianteiras dos coelhos (controle e operada), através do colimador pinhole.

$\mathrm{Na}$ análise da contagem total ao pinhole em 4 semanas pós-operatório a diferença de contagem entre a pata esquerda (26.100 +/- 4.026 contagens, ctgs) e direita (63.000 +/- 15.914 ctgs) foi significante (Paired-Samples TTest, $p \leq 0,00002)$.

$\mathrm{Na}$ análise da contagem total ao pinhole em 8 semanas pós-operatório a diferença de contagem entre a pata esquerda (23.500 +/- 3.628 ctgs) e direita $(38.500$ +/- 6.078 ctgs) foi significante (Paired-Samples T-Test, $\mathrm{p} \leq 0,000004)$. 
$\mathrm{Na}$ análise da contagem total ao pinhole em 12 semanas pósoperatório a diferença de contagem entre a pata esquerda $(22.150+/-2.708$ ctgs) e direita (32.500 +/- $6.244 \mathrm{ctgs})$ foi significante (Paired-Samples T-Test, $p \leq 0,00001)$.

GRÁFICO 2 - Contagens totais de radiação externa nas patas operada (direita) e controle (esquerda) através do colimador pinhole.

(A)

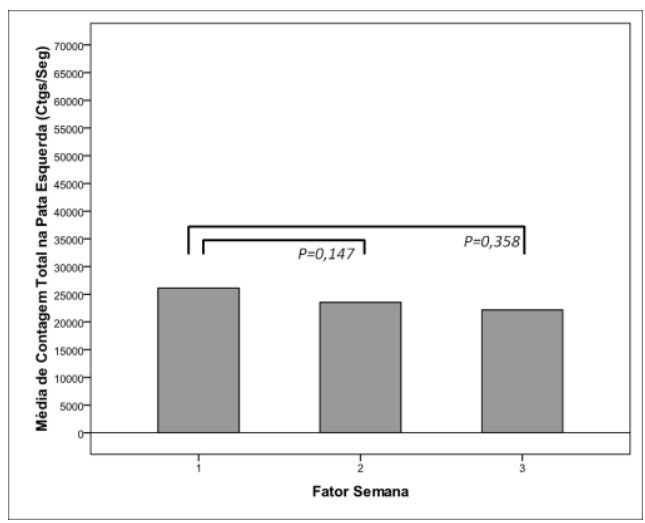

(B)

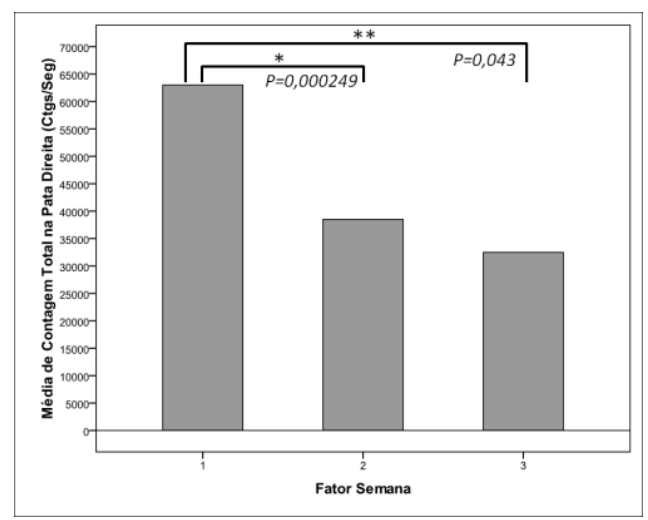

\subsection{Avaliação por imagem cintilográfica da biodistribuição relativa do} radiofármaco nos tecidos moles de ambas as patas, controle e operada.

A radiação de fundo dos tecidos moles não apresentou diferença significante na pata controle, seja em $4(2,30+/-0,91 \mathrm{ctgs} /$ pixel), $8(2,06+/-$ 0,64 ctgs/pixel) e 12 semanas (1,85+/-0,62 ctgs/pixel) (One-Way ANOVA, $\mathrm{p} \leq 0,408$ ) (GRÁFICO $3, A$ ). Esta mesma radiação de fundo também não apresentou diferença significante na pata operada entre 4 (2,56+/-0,62 ctgs/pixel) e 8 semanas (2,25+/-0,52 ctgs/pixel) (One-Way ANOVA $p \leq 0,242$ ) e entre 8 e 12 semanas (One-Way ANOVA, $p \leq 0,114$ ), porém foi significante entre 4 e $12(1,89+/-0,42$ ctgs/pixel) semanas (One-Way ANOVA, $p \leq 0,012)$ (GRÁFICO 3, B).

A análise comparativa, agora, das radiações nos tecidos moles entre as patas controle e operada mostrou que não houve diferenças significantes 
entre as mesmas (One-Way Anova, $p \leq 0,950$ ), evidenciando que provavelmente as diferenças nas Contagens Totais ao Colimador Pinhole deve-se notoriamente às contagens relativas aos ossos do que em relação aos tecidos moles.

GRÁFICO 3 - Biodistribuição do radiofármaco nos tecidos moles de ambas as patas, controle e operada.

(A)

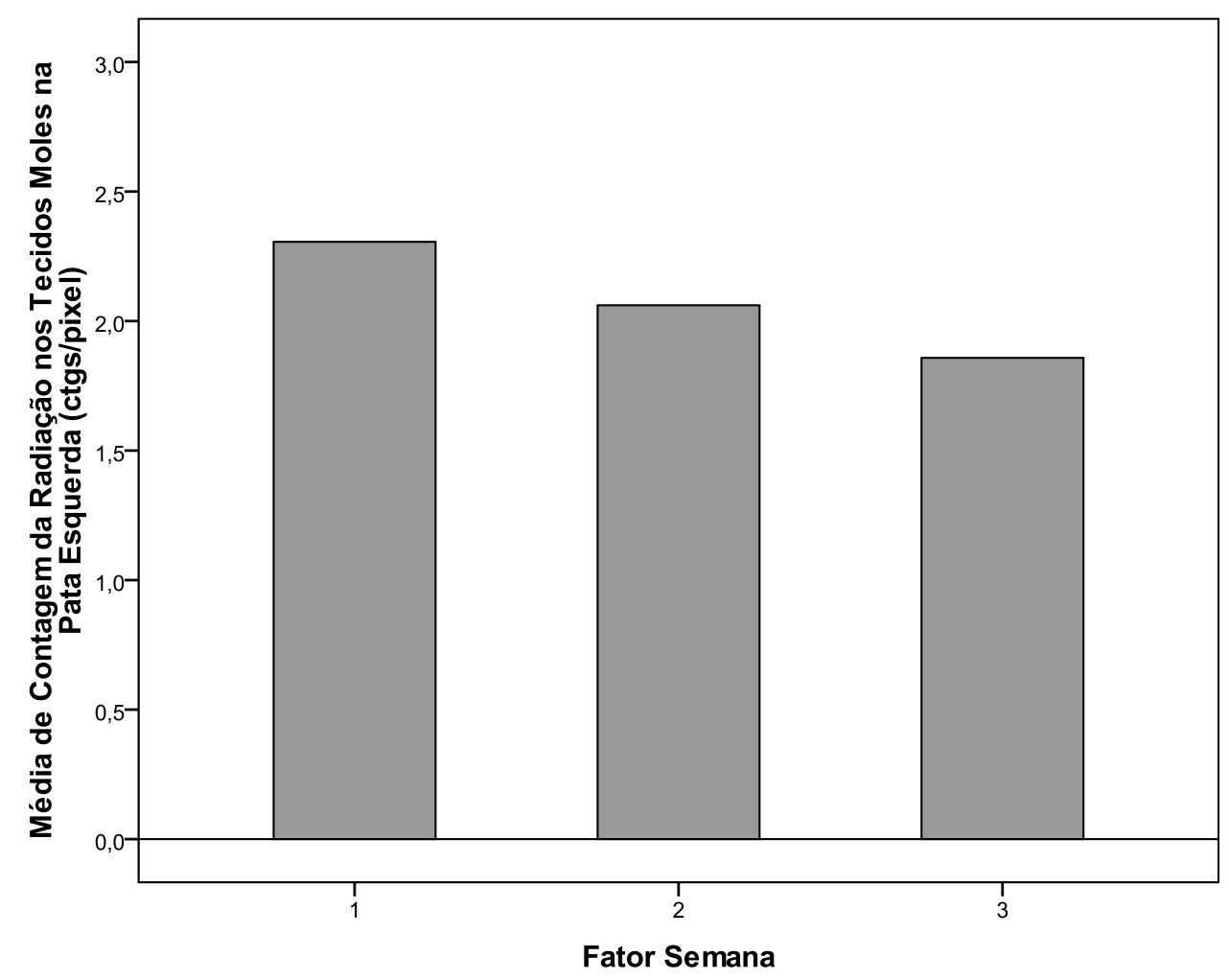


(B)

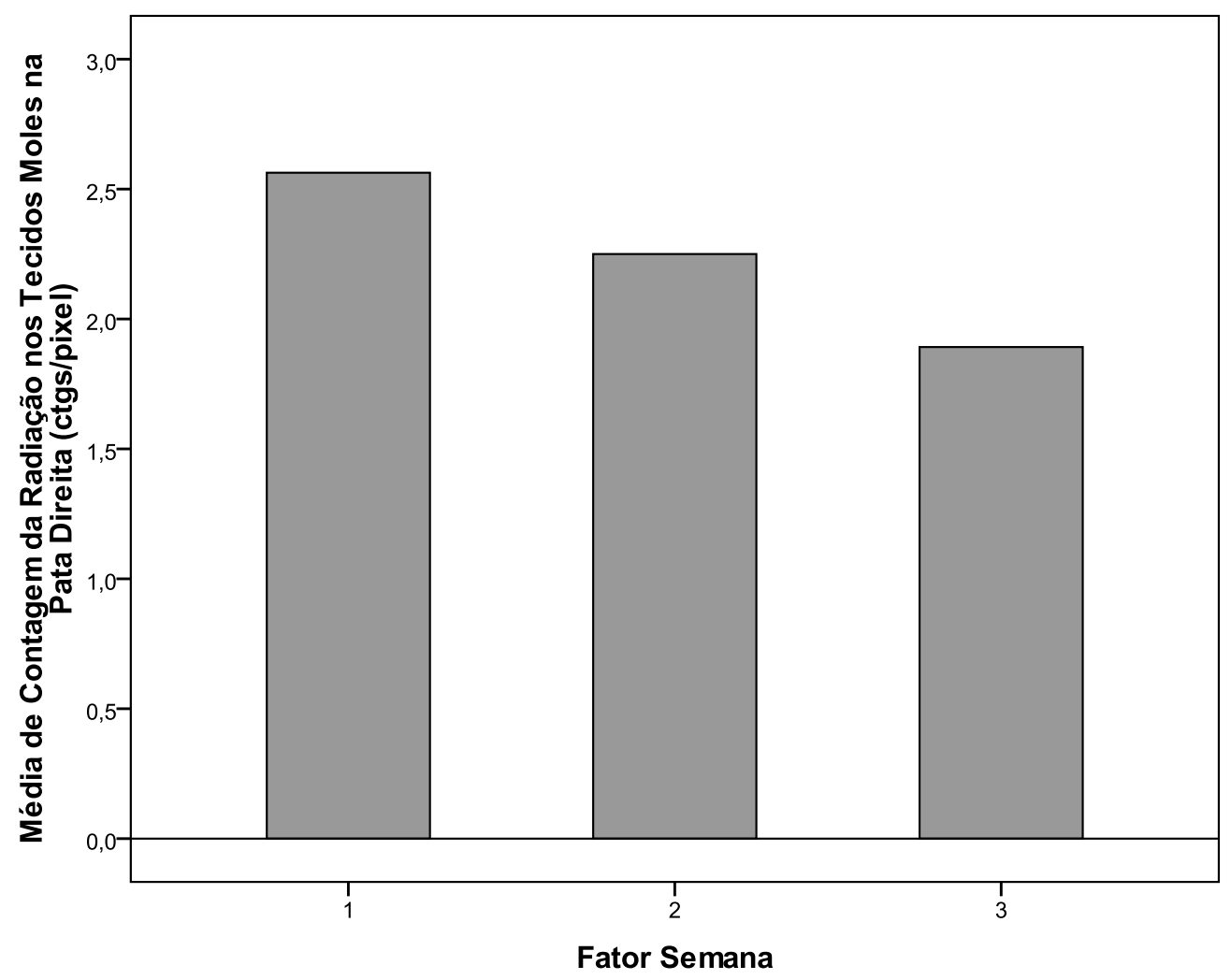

4.3. Avaliação da osteogênese dos ossos rádio e ulna em ambas as patas, controle e operada, na $4^{\mathrm{a}}, 8^{\mathrm{a}}$ e $12^{\mathrm{a}}$ semanas pós-operatórias.

A análise da atividade osteogênica nas quatro regiões ósseas de interesse de ambas as patas (ROls 01, 02, 03 e 04) é apresentada no GRÁFICO 4 (A a D). Estas atividades osteogênicas foram mensuradas nas

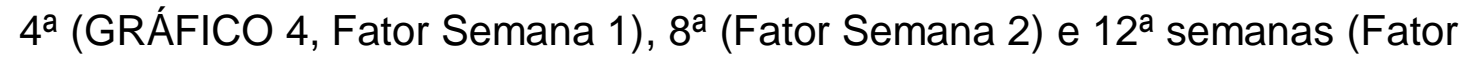
Semana 3).

No ROI-01 (GRÁFICO 4, A), que mede a osteogênese em toda a extensão dos ossos das patas anteriores, podemos observar que a pata 
esquerda apresentou média de Taxa de Contagens (ctgs/pixel) (+/- Desvio Padrão) de 6,84+/-1,05 em 4 semanas, 6,35+/-1,55 para 8 semanas e 5,90+/1,40 em 12 semanas (One-Way ANOVA, $p \leq 0,31$ ). A pata direita apresentou média +/- DP de 36,18+/-13,05 em 4 semanas, 16,73+/-2,81 em 8 semanas e 12,91+/-4,05 em 12 semanas (One-Way ANOVA, $p \leq 0,000001$ ). Esta diferença significante foi observada em detalhe tanto entre a $4^{\mathrm{a}}$ e $8^{\mathrm{a}}$ semanas (One-Way ANOVA, $p \leq 0,0002$ ), entre a $8^{\mathrm{a}}$ e $12^{\mathrm{a}}$ semanas (One-Way ANOVA, $p \leq 0,02)$ e, também, entre as $4^{\underline{a}}$ e $12^{\underline{a}}$ semanas (One-Way ANOVA, $p \leq 0,0002)$.

No ROI-02 (GRÁFICO 4, B), que mede a osteogênese no terço distal dos ossos das patas anteriores, podemos observar que a pata esquerda apresentou média +/- DP de 6,74+/-1,32 em 4 semanas, 6,69+/-2,24 para 8 semanas e 5,80+/-1,51 em 12 semanas (One-Way ANOVA, $p \leq 0,40$ ). A pata direita apresentou média +/- DP de 19,97+/-6,30 em 4 semanas, 10,32+/-2,58 em 8 semanas e 7,98+/-1,54 em 12 semanas (One-Way ANOVA, $p \leq 0,00000086)$. Esta diferença significante foi observada em detalhe tanto entre a $4^{\underline{a}}$ e $8^{\text {a }}$ semanas (One-Way ANOVA, $p \leq 0,0003$ ), entre a $8^{\underline{a}}$ e $12^{\underline{a}}$ semanas (One-Way ANOVA, $p \leq 0,03$ ) e, também, entre as $4^{\text {a }}$ e $12^{\text {a }}$ semanas (One-Way ANOVA, $p \leq 0,00002$ ).

No ROI-03 (GRÁFICO 4, C), que mede a osteogênese no terço médio dos ossos das patas anteriores, podemos observar que a pata esquerda apresentou média +/- DP de 7,24+/-0,88 em 4 semanas, 6,30+/-1,51 para 8 semanas e 5,93+/-1,06 em 12 semanas (One-Way ANOVA, $p \leq 0,05)$. A pata direita apresentou média +/- DP de 46,91+/-18,04 em 4 semanas, 22,06+/5,04 em 8 semanas e 15,67+/-4,65 em 12 semanas (One-Way ANOVA, $p \leq 0,0000022)$. Esta diferença significante foi observada em detalhe tanto entre a $4^{\mathrm{a}}$ e $8^{\mathrm{a}}$ semanas (One-Way ANOVA, $p \leq 0,001$ ), entre a $8^{\mathrm{a}}$ e $12^{\mathrm{a}}$ semanas (One-Way ANOVA, $p \leq 0,09)$ e, também, entre as $4^{\mathrm{a}}$ e $12^{\mathrm{a}}$ semanas (One-Way ANOVA, $p \leq 0,00005)$.

No ROI-04 (GRÁFICO 4, D), que mede a osteogênese no terço proximal dos ossos das patas anteriores, podemos observar que a pata 
esquerda apresentou média +/- DP de 6,89+/-1,61 em 4 semanas, 5,77+/0,95 para 8 semanas e 5,05+/-1,43 em 12 semanas (One-Way ANOVA, $p \leq 0,02)$. A pata direita apresentou média +/- DP de 42,36+/-19,71 em 4 semanas, 17,66+/-4,69 em 8 semanas e 14,47+/-6,76 em 12 semanas (OneWay ANOVA, $p \leq 0,000036)$. Esta diferença significante foi observada em detalhe tanto entre a $4^{\mathrm{a}}$ e $8^{\mathrm{a}}$ semanas (One-Way ANOVA, $p \leq 0,001$ ), quanto entre as $4^{a}$ e $12^{\text {a }}$ semanas (One-Way ANOVA, $p \leq 0,01$ ). Não foi observada diferença entre a $8^{\mathrm{a}}$ e $12^{\mathrm{a}}$ semanas (One-Way ANOVA, $p \leq 0,23$ ).

GRÁFICO 4- Taxas de Contagem (ctgs/pixel) no osso inteiro e nos terços distal, médio e proximal dos ossos rádio e ulna, das patas controle e operada, nas quarta, oitava e décima segunda semanas.

PATA ESQUERDA

(A) ROI-01

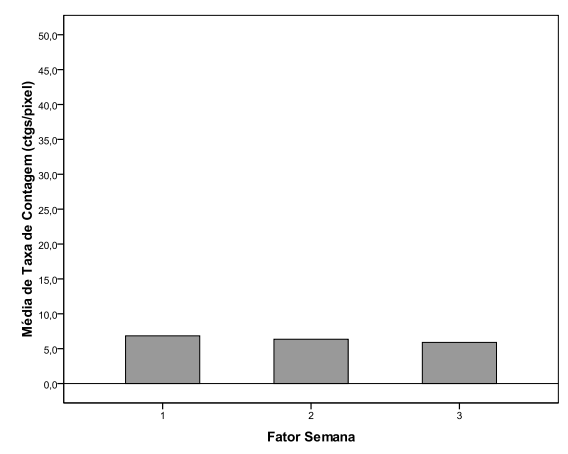

(B) ROI-02

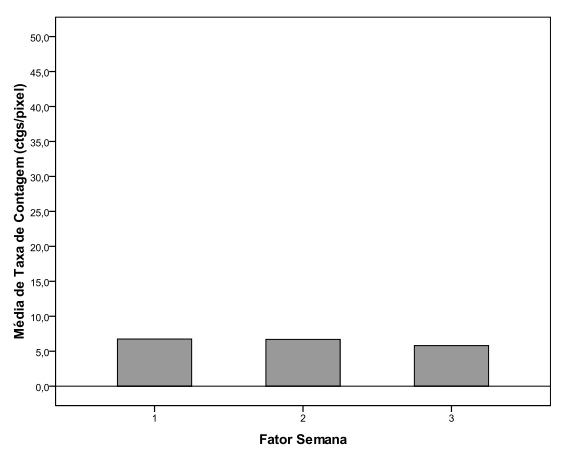

PATA DIREITA

(C) ROI-03

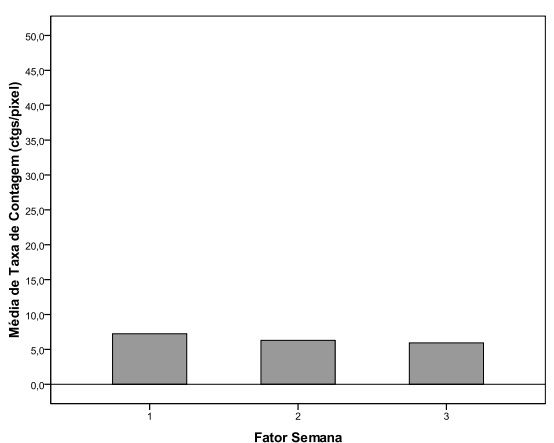

(D) ROI-04

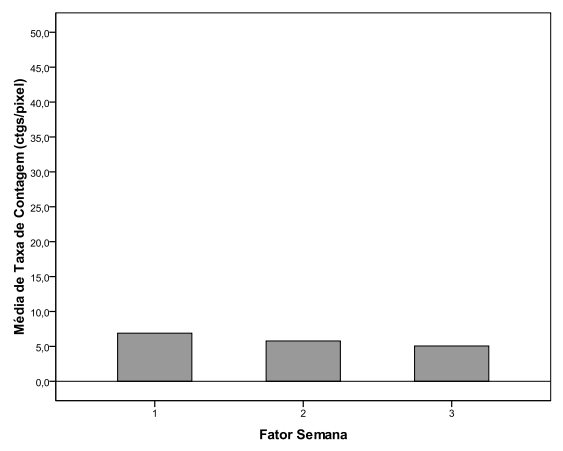

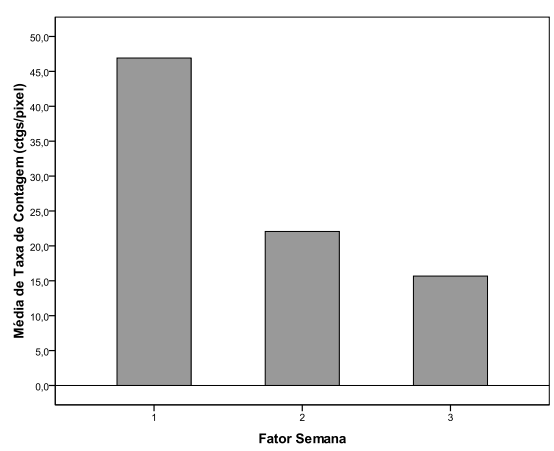

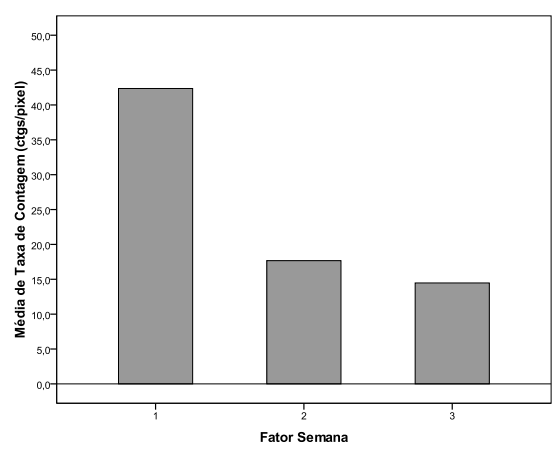




\section{DISCUSSÃO}

O presente projeto de pesquisa teve como objetivo avaliar a contribuição da Cintilografia Óssea na avaliação da osteogênese durante o processo regenerativo pós-osteotomia na pata direita de coelhos. O objetivo geral foi o de protocolar a técnica de Cintilografia Óssea em Coelhos e o de propor métodos quantitativos de análise do metabolismo ósseo em condições normais (Grupo Controle) e sob condições que estimulem a regeneração óssea (Grupo Operado).

Para tanto, foi realizado um estudo prospectivo no qual 10 coelhos foram submetidos a osteotomia no osso Ulna da pata direita e Cintilografias Ósseas seriadas foram adquiridas nos tempos 4, 8 e 12 semanas após a intervenção cirúrgica. Medidas quantitativas da concentração do radiofármaco foram realizadas tanto nos tecidos moles quanto nas estruturas ósseas avaliadas, sejam na pata controle (Pata E) ou na pata operada (Pata D).

\subsection{Ausência de influência do intervalo de tempo entre injeção do radiofármaco e aquisição das imagens sobre a quantificação da osteogênese.}

Para garantir que os 3 Grupos (4, 8 e 12 semanas) foram expostos às mesmas condições de investigação, a variável mais relevante que poderia interferir nas quantificações dentre os três grupos foi avaliada. Trata-se do intervalo de tempo decorrido entre a injeção do radiofármaco e o início da aquisição das imagens. Esta variável é de grande importância, uma vez que a diferença na taxa de contagem entre o osso e o tecido mole é diretamente proporcional ao tempo decorrido entre a injeção do radiofármaco e a aquisição das imagens. Isto ocorre porque os tecidos moles apresentam um clareamento do radiofármaco em velocidade maior do que a do radiofármaco extraído pela matriz óssea. Com isto, se um grupo apresentasse um intervalo maior de tempo, as quantificações poderiam ser menores neste grupo tardio. 
A análise, portanto, dos intervalos de tempo evidenciaram que os 3 Grupos são praticamente homogêneos e as diferenças entre eles não foram significantes (GRÁFICO 1). Dentre os 3 Grupos, o grupo de 4 semanas foi o que apresentou um intervalo ligeiramente maior, ou seja, de 04:18h. Este fato provavelmente deveu-se à curva de aprendizado, na qual o período despendido no posicionamento dos Coelhos no início do projeto foi um pouco maior, período este minimizado com a melhora prática na aquisição das imagens dos coelhos.

\subsection{Biodistribuição global e relativa do radiofármaco em ambas as patas dianteiras dos coelhos (controle e operada), através do colimador pinhole.}

Quanto à Contagem Total ao Pinhole, o que se pode interpretar dos resultados é que, como foi observado, todas as 3 medidas adquiridas, ie., $4^{\mathrm{a}}$, $8^{\mathrm{a}}$ e $12^{\mathrm{a}}$ semanas pós-operatórias exibiram contagens significativamente maiores nas patas operadas (direitas) que nas patas controle (esquerdas) (GRÁFICO 2). Este achado já nos comprova a base farmacológica do radiofármaco MDP-99mTc o qual é utilizado devido ao seu tropismo pela matriz orgânica, a qual é responsável pela neoformação óssea. Este é um achado esperado, dado a plausibilidade biológica para o uso deste radiofármaco. Ou seja, em uma pata na qual ocorreu algum tipo de intervenção óssea, o mais racional é que o acúmulo ou concentração deste radiofármaco esteja aumentada em relação à pata controle (RIGGS \& KELLY, 1982).

A captação de ${ }^{99 \mathrm{~m}} \mathrm{Tc}-\mathrm{MDP}$ está diretamente ligada ao fluxo sanguíneo no osso e à taxa de osteogênese (MCCARTHY \& HUGUES, 1983). aumento regional do fluxo sanguíneo e da atividade osteoblástica está presente após a lesão óssea e durante a reparação posterior, e é responsável pelo o aumento da captação de radionuclídeos no local da fratura (GENNARI, 1985). 
Acredita-se que o mecanismo pelo qual o ${ }^{99 \mathrm{~m}} \mathrm{Tc}-\mathrm{MDP}$ se conecta ao osso seja através de ligações químicas nas superfícies dos cristais de hidroxipatita.

\subsection{Biodistribuição relativa do radiofármaco nos tecidos moles de ambas as patas, controle e operada, baseando-se nas imagens cintilográficas obtidas das mesmas.}

Uma importante análise, na avaliação da biodistribuição relativa do radiofármaco entre ambas as patas é a avaliação da radiação de fundo, ou seja, radioatividade presente nos tecidos moles. Não houve diferença nesta biodistribuição entre as duas patas (One-Way ANOVA, $p \leq 0,950$ ). Este resultado foi importante, pois leva-nos a inferir que as diferenças observadas entre as patas nas Contagens Totais ao Colimador Pinhole deve-se na verdade às contagens observadas nos ossos, demonstrando este achado à plausibilidade biológica para a utilização deste radiofármaco, um traçador biológico para tecidos ósseos. Esta afirmação talvez não tenha valor para a fase aguda pós operatória, na qual o fluxo sanguíneo talvez se já também determinante para o aumento da biodistribuição maior do radiofármaco na pata operada, em concordância com os achados de MCCARTHY \& HUGUES, que afirmam que a captação de ${ }^{99 m}$ Tc-MDP está diretamente ligada ao fluxo sanguíneo no osso e à taxa de osteogênese.

\subsection{Avaliação da osteogênese nos ossos rádio e ulna, de ambas as patas, controle e operada, nas $4^{\mathrm{a}}, 8^{\mathrm{a}}$ e $12^{\mathrm{a}}$ semanas pós-operatórias.}

A cintilografia demonstrou ser uma ferramenta bastante sensível às diferenças quantitativas reais de osteogênese entre as patas controle e operada, descontadas a radiação de fundo dos tecidos moles.

Nos ROls 01 e 02 da pata controle não houve diferenças significantes de osteogênese ao longo da $4^{\mathrm{a}}, 8^{\mathrm{a}}$ e $12^{\mathrm{a}}$ semanas. Entretanto, no ROI 03 houve uma tendência a apresentar diferenças (One-Way ANOVA, $p \leq 0,05$ ), 
que se tornaram evidentes no ROI 04 (One-Way ANOVA, $p \leq 0,02$ ). Este foi um achado bastante interessante, pois significa que também a pata controle sofre alterações osteogênicas ao longo das semanas, apos a intervenção cirúrgica. Esclarecendo em termos clínicos, interpretamos que a redução da osteogênese nos terços médio e próxima da pata controle ao longo das semanas, possa representar o efeito metabólico ósseo da imobilidade motora desta pata controle provocada pela restrição gerada pela osteotomia e pela restrição de espaço para movimentação na gaiola. A limitação cirúrgica de movimento de uma pata levaria à redução metabólica da pata contralateral sadia. Em particular, acreditamos que a redução de tração motora nos dois terços proximais (áreas de inserção de musculaturas flexoras) dos ossos das patas controles, possa ter levado à diminuição da demanda de carga nestas regiões e redução da remodelação óssea nestas regiões de interesse.

Por outro lado, na pata operada, a resposta metabólica óssea ou osteogênese secundária à osteotomia foi acentuada. Tomando-se por base o ROI 01, que mede toda a extensão do osso operado, a maior taxa de osteogênese foi observada na $4^{a}$ semana pós-operatória e, desta fase em diante, observa-se redução gradual porém significante da osteogênese a cada período avaliado, ie., na $8^{\mathrm{a}}$ e $12^{\mathrm{a}}$ semanas (GRÁFICO 4, A - PATA OPERADA). Esta redução gradual e contínua da osteogênese denota o processo de resolução da cicatrização óssea. Por estes resultados, o presente estudo evidencia a alta sensibilidade do método cintilográfico em avaliar as diferenças temporais na osteogênese após uma intervenção cirúrgica. 


\section{CONCLUSÕES}

6.1. O método da cintilografia óssea foi sensível ao evidenciar alterações funcionais tanto nos tecidos moles quanto no tecido ósseo, de ambas as patas, controle e operadas, ao longo de 3 momentos de avaliação, com 4, 8 e 12 semanas;

6.2. A atividade radioativa de fundo nos tecidos moles foi similar nas patas direita e esquerda. Ainda assim, acreditamos ser fundamental a semiquantificação da mesma, para que possamos subtraí-la das semiquantificações das demais regiões de interesse sobre os ossos;

6.3. A osteogênese nas patas operadas apresentou sua atividade máxima na 4ª semana pós-operatória e, a partir desse momento, a atividade osteogênica apresentou significativa queda nas $8^{\underline{a}}$ e $12^{\underline{a}}$ semanas subseqüentes;

6.4. A pata controle apresentou redução da sua osteogênese, desde a $4^{a}$ até a $12^{-a}$ semanas, e tal fato pode ter sido decorrente da limitação dos coelhos em gaiolas no período pós-operatório, bem como ter sido resultando da maior limitação de movimento causado pela lesão cirúrgica na pata operada. 


\section{LIMITAÇÕES DO ESTUDO E SUGESTÕES PARA PESQUISAS FUTURAS}

Uma limitação importante a considerar, no presente trabalho, foi a ausência de avalição cintilográfica na primeira, segunda e terceira semanas pós-operatória. O projeto intencionou construir uma curva metabólica da osteogênese, avaliando sua evolução temporal. Entretanto somente após todas as atividades experimentais terem sido adquiridas e as imagens cintilográficas analisadas, fomos perceber que a atividade máxima encontrada em 4 semanas poderá ser precedida por possíveis atividades máximas não evidenciadas precedentemente.

Sugerimos que em estudos futuros que outras fases pós-operatórias (eg., $2^{\mathrm{a}}, 6^{\mathrm{a}}, 10^{\mathrm{a}}$ e $14^{\mathrm{a}}$ semanas) sejam avaliadas em protocolos similares. Isto poderá permitir o melhor delineamento da osteogênese neste modelo experimental após lesão cirúrgica. Esta sugestão se fundamenta no fato de que, quando fizemos as análises com 4, 8 e 12 semanas, a atividade máxima já tinha sido observada com 4 semanas e os períodos precedentes não foram semi-quantificados. Será que a atividade de máxima osteogênese realmente é com 4 semanas, ou poderia ser com 3 semanas. Estas são conjecturas para estudos futuros. 


\section{BIBLIOGRAFIA*}

AUGAT, P.; MARGEVICIUS, K.; SIMON J et al. (1998). Local tissue properties in bone healing: influence of size and stability of the osteotomy gap. J Orthop Res 16: 475-81.

BAHK, Y.W. (1994). Combined scintigraphic and radiographic diagnosis of bone and joint diseases. Springer, Heidelberg.

BLAU, M.; NAGLER, W.; BENDER, M. A. (1962). Fluorine-18: a new isotope for bone scanning. Journal of Nuclear Medicine 3: p.332-334.

CALIXTO, S.P. (2007). Estudo do efeito do campo elétrico pulsado no reparo ósseo em tibia de ratos. Tese (Mestrado) - Programa de pós-graduação Interunidades em Bioengenharia da Escola de Engenharia de São Carlos Universidade de São Paulo, São Carlos.

CAO, B.; BRUDER, J.; HUARD, J. (2004). Muscle stem cells can act as antigen-presenting cells: implication for gene therapy. Gene Ther 11: 132130.

CHARKES, N. D. (1969). Some differences between bone scans made with $87 \mathrm{mSr}$ and 85Sr. Journal of Nuclear Medicine 10: p.491-494.

CHIEVITZ, O.; HEVESY, G. (1935). Radioactive indicators in the study of phosphorus metabolism in rats. Nature 136: p.754-755.

CLARKE, B. (2008). Normal Bone Anatomy and Physiology. Clin J Am Soc Nephrol $3,131-139$.

EINHORN, T.A. (1994). Bone metabolism and metabolic bone disease. In: Frymoyer, F.W. Orhtophaedic Knowledge update 4 home study sillabus. Rodemont: American Academy of Orthopaedic Surgeons. p.69-88.

ERIKSEN EF, AXELROD DW, MELSEN F. (1994) Bone Histomorphometry, New York, Raven Press, pp 1-12.

FERGUSON C, Alpern E, Miclau T, Helms JA. (1999). Does adult fracture repair recapitulate embryonic skeletal formation? Mech Dev 87: 57-66.

FLEMING, W. H.; MCIIRAITH, J.D.; KING, E. R. (1961). Photoscanning of bone lesions utilising strontium-85. Radiology 77: p.635-636.

FROST, H. (1991). A new direction for osteoporosis research: a review and proposal. Bone, Elmsford, v.12, n.6, p. 429-437.

GENNARI, C. (1985) Glucocorticoids and bone. In: PECK, W., Ed. Bone and Mineral Research, vol.3. New York: Elsevier. 
GINEBRA, M.P.; PLANELL, J.A.; PARICIO, C. (2000). Structure and mechanical properties of cortical bone. In: Elices,M. (Ed.). Structural Biological Materials. New York: Pergamon. Cap.3, p.33-71.

LIND, M. (1998). Growth factor stimulation of bone healing: effects on osteoblasts, osteotomies and implants fixation. Acta Orthopaedica Scandinavica, Cambridge, v.69, p.1-37, Oct. Supplement 283.

LUCCHINETTI, E. (2001). Composite models of bone properties. In: JEE, W. Bone mechanics handbook. Boca Raton: CRC Press. Cap.3, p.101-119.

MANDELL, G.A.; HARCKE, H.T.; HUDH, J.; KUMAR, S.J.; MAAS, K.W. (1990). Detection of talocalcaneal coalitions by magnification bone scintigraphy. Journal of Nuclear Medicine 31: p.1797-1801.

MCCARTHY, I.D.; HUGHES, S.P. (1983) The role of skeletal blood flow in determining the uptake of ${ }^{99 \mathrm{~m}}$ Tc-MDP. Calcif Tissue Int 35: p.508-511.

RIGGS, S.A.; KELLY, P.J.(1983) The relationship between blood flow and ${ }^{99 \mathrm{~m}}$ TC-MDP uptake in bone scanning. Journal of Nuclear Medicine 23: p.77.

STOREY, G.; MURRAY, I.P.C. (2004). Bone scintigraphy: the procedure and interpretation. In: Ell, P.J.; Gambhir, S.S. Nuclear Medicine in clinical diagnosis and treatment. vol.1, 3rd Ed., p.593-619.

SUBRAMANIAN, G.; MACFEE, J. G. (1971). A new complex of 99mTc for skeletal imaging. Radiology 99: p.192-196.

TAICHMAN, R.S.(2005). Blood and bone: Two tissues whose fates are intertwined to create the hematopoietic stem cell niche. Blood 105: 26312639.

TOSOUNIDIS, T.; KONTAKIS, $\quad$ G.; NIKOLAOU, V.; PAPATHANASSOPOULOS, A.; GIANNOUDIS, P. (2009). Fracture Healing and bone repair: an update. Trauma, 145-156.

ZIESSMAN, H.A.; O'MALLEY, J.P.; THRALL, J.H. (2006). Nuclear Medicine: The requisites in radiology. 3rd Ed., p.34-51.

*De acordo com o estilo Vancouver 